\title{
Are patients willing to remove, and capable of removing, their own nonabsorbable sutures?
}

\author{
Peter Macdonald, MD*; Nadia Primiani, MD ${ }^{\dagger}$; Adam Lund, BSc, MD, MDE ${ }^{\ddagger}$
}

ABSTRACT

Objectives: Providing patients with instructions and equipment regarding self-removal of nonabsorbable sutures could represent a new efficiency in emergency department (ED) practice. The primary outcome was to compare the proportion of patients successfully removing their own sutures when provided with suture removal instructions and equipment versus the standard advice and follow-up care. Secondary outcomes included complication rates, number of physician visits, and patient comfort level.

Methods: This prospective, controlled, single-blinded, pseudorandomized trial enrolled consecutive ED patients who met the eligibility criteria (age $>19$ years, simple lacerations, nonabsorbable sutures, immunocompetent). The study group was provided with wound care instructions, a suture removal kit, and instructions regarding suture self-removal. The control group received wound care instructions alone. Outcomes were assessed by telephone contact at least 14 days after suturing using a standardized questionnaire.

Results: Overall, 183 patients were enrolled (93 in the intervention group; 90 in the control group). Significantly more patients performed suture self-removal in the intervention group $(91.5 \% ; 95 \% \mathrm{Cl} 85.4-97.5)$ compared to the control group (62.8\%; 95\% Cl 52.1-73.6) ( $p<0.001$ ). Patients visited their physician less often in the intervention group (9.8\%; 95\% Cl 3.3-16.2) compared to the control group (34.6\%; 95\% Cl 24.1-45.2\%) ( $p<0.001)$. Complication rates were similar in both groups.

Conclusion: Most patients are willing to remove, and capable of removing, their own sutures. Providing appropriate suture removal instructions and equipment to patients with simple lacerations in the ED appears to be both safe and acceptable.

\section{RÉSUMÉ}

Objectifs: Le fait de donner des instructions aux patients sur la façon d'enlever eux-mêmes les points de suture non résorbables et de leur fournir le matériel nécessaire représenterait un nouveau moyen d'efficience aux services des urgences. Le principal critère d'évaluation visait à comparer la proportion de patients ayant réussi à bien enlever leurs propres points de suture après avoir reçu des instructions appropriées sur la façon de le faire et le matériel nécessaire, avec celle ayant reçu les conseils et les soins de suivi habituels. Les critères d'évaluation secondaires comprenaient le taux de complications, le nombre de consultations médicales, et le degré de confort des patients.

Méthodes: Il s'agit d'un essai comparatif, prospectif, mené à simple insu et selon un schéma pseudoaléatoire chez des patients consécutifs, traités à l'urgence, qui répondaient aux critères de sélection (âge $>19$ ans, lacérations simples, points de suture non résorbables, compétence immunitaire). Le groupe expérimental a reçu des instructions sur les soins de la plaie, une trousse pour enlever les points de suture, et des instructions sur la façon de les enlever eux-mêmes. Le groupe témoin a reçu des instructions sur les soins de la plaie seulement. Les résultats ont été évalués par communication téléphonique, au moins 14 jours après la suture, à I'aide d'un questionnaire uniforme.

Résultats: Au total, 183 patients ont participé à l'étude (93 dans le groupe expérimental; 90 dans le groupe témoin). Un nombre significativement plus élevé de patients ont enlevé eux-mêmes les points de suture dans le groupe expérimental (91.5\%; IC à 95\% 85.4-97.5) que dans le groupe témoin (62.8\%; IC à 95\%: 52.1-73.6) ( $p<0.001)$. Les patients dans le groupe expérimental ont consulté moins souvent leur médecin $(9.8 \%$; IC à $95 \% 3.3-16.2)$ que ceux dans le groupe témoin $(34.6 \%$; IC à $95 \% 24.1-45.2 \%)(p<0.001)$. Le taux de complications était comparable dans les deux groupes.

Conclusion: La plupart des patients sont disposés à enlever leurs propres points de suture et sont capables de le faire. II semble donc que le fait de donner des instructions appropriées sur la façon d'enlever les points de suture et le matériel nécessaire aux patients souffrant de lacérations simples et traités à l'urgence soit un moyen à la fois sûr et acceptable.

Keywords: suture, suture removal, wound care

From the *Department of Emergency Medicine, Royal Columbian Hospital, New Westminster, BC; †Department of Family Practice, University of British Columbia, Vancouver, BC; $\neq$ Department of Emergency Medicine, University of British Columbia, Vancouver, BC.

Correspondence to: Dr. Peter Macdonald, 330 East Columbia Street, New Westminster, BC V3L 3W7; peter.macdonald@fraserhealth.ca.

This article has been peer reviewed.

(c) Canadian Association of Emergency Physicians 
It has been reported that lacerations account for approximately $12 \%$ of all emergency department (ED) visits. ${ }^{1}$ As many as 3 million (United Kingdom) and more than 2 million (United States) traumatic wounds are treated in the ED annually.,3 Patients who are sutured with nonabsorbable sutures in the ED are often asked to follow up with their family doctor or local medical clinic for suture removal. Providing patients with the necessary knowledge and equipment may enable some patients to remove their own sutures at home. Suture self-removal could represent significant cost and time savings to the health care system and the patient.

The primary objective of this study was to determine the proportion of patients who would be successful at removing their own nonabsorbable sutures when given the appropriate suture removal instructions and equipment versus those given only the usual follow-up care. Secondary objectives included whether there were complications related to self-removal of sutures, if self-removal of sutures avoided a visit to a physician, and the patient's self-reported comfort level with suture self-removal.

Prior to the commencement of the study, a survey was distributed to all the emergency physicians (EPs) working at the two participating hospitals. This survey sought to clarify the current practice of physicians with respect to the type of suture material typically used, information given to patients on discharge, and where patients were instructed to go for suture removal. ${ }^{4}$ Twenty-six of 30 EPs (86.7\%) completed the survey.

The results for the use of nonabsorbable sutures and the timing of suture removal were consistent with the recommended practice from the emergency medicine literature. ${ }^{1,2,5-8}$ All physicians surveyed agreed that suture self-removal is safe and simple and that most patients should be capable of removing their sutures.

\section{METHODS}

\section{Setting}

Two EDs were used in this study: a tertiary trauma centre and a community hospital. These hospitals average over 60,000 and 40,000 emergency patient visits per year, respectively.

\section{Sample}

Consecutive patients over 19 years of age who presented to the ED with a laceration sutured using nonabsorbable sutures were considered for entry into the study. Patients were excluded from the study if they were unable to give consent secondary to alcohol, drugs, or inability to speak English; if they had complicated lacerations or lacerations that required close medical supervision; if the lacerations were inaccessible to the patient (i.e., scalp, back, or buttock); if they could not be contacted by telephone for followup; or if they were immunocompromised (i.e., had diabetes mellitus or AIDS, had undergone chemotherapy, or were on steroid medications).

\section{Data collection}

Informed consent, current telephone contact information, patient demographics, wound location, and suggested timing for suture removal were obtained at the time of enrolment. EPs enrolled consenting patients into either the study or the control group in a pseudorandomized manner based on an odd/even day design.

\section{Interventions}

Patients were discharged with instructions on wound care only (control group, even days) or with wound care instructions, ${ }^{9}$ a suture removal kit, and instructions on how to remove sutures (study group, odd days). ${ }^{10,11}$

\section{Outcome assessment}

The primary outcome was to compare the proportion of patients successfully removing their own sutures when provided with suture removal instructions and equipment. Secondary outcomes included complication rates, number of physician visits, and patient comfort level versus a control group.

Telephone follow-up of both groups of patients was undertaken a minimum of 14 days postsuturing. Patients were asked a series of scripted questions regarding who removed their sutures, the number of physician visits, work absence related to physician visits, complications related to the sutures, and their comfort level with suture self-removal. Patientreported successful self-removal and removal with the help of a nonmedical person such as a family member or friend were classified as "successful" self-removal. 


\section{Statistical considerations}

\section{Sample size}

The sample size for this study was derived from the findings of Albert and colleagues in which approximately $24 \%$ of patients reported willingness to remove their own sutures without instruction or facilitating equipment and as many as $46 \%$ reported that they would remove their own sutures if given the means to do so. ${ }^{12}$ On the basis of their results, it was determined that 80 patients in each group would provide sufficient power $($ power $=0.80$ ) to detect a difference between the proportion of the end-point of suture self-removal of 0.24 in the control group and 0.46 in the intervention group. This was calculated using a twosided chi-square test with continuity correction and with a significance level of 0.05 .

\section{Analyses}

Demographic and outcome data were summarized using descriptive statistics, including median and interquartile range or mean and standard deviation for continuous variables and proportions with $95 \%$ confidence intervals for categorical variables. Treatment group means and proportions in the demographic, primary, and secondary outcomes were compared using two-tailed $t$-, chi-square, or Fisher exact tests as appropriate using SPSS version 14.0 (SPSS Inc, Chicago, IL). An intention-to-treat strategy was used to assess the primary and secondary outcomes.

\section{Ethics}

This study received approval from the Fraser Health Authority Ethics Review Board on March 30, 2010, and was registered with ClinicalTrials.gov. All study forms and information concerning patients followed the Fraser Health Authority Ethics code on confidentiality.

\section{RESULTS}

Figure 1 shows a breakdown of the number of patients considered for the study, eligible patients, refusals to participate, and patients lost to follow-up. The final control group was composed of 78 patients, whereas the study group had 82 patients. The groups were similar with respect to gender and age (Table 1). The location of the wounds was similar in both groups, with the majority of the wounds located on the extremities (see Table 1).

Forty-nine $(62.8 \%$; 95\% CI 52.1-73.6) patients in the control group and 75 (91.5\%; 95\% CI 85.4$97.5 \%$ ) patients in the intervention group successfully achieved suture self-removal, which was statistically significant (Table 2). Two patients in the intervention group should have been excluded because they did not have "simple" lacerations and therefore did not meet the inclusion criteria. The first patient suffered a crush injury with a compound fracture of his fingertip. This led to three visits to his family physician as the sutures became embedded and pieces of bone were extruding from the wound. The other patient had diabetes and suffered a dog bite to her upper extremity. Excluding these two patients from the study would have increased the suture self-removal proportion to $95 \%$ in the intervention group.

In the control group, $29(34.6 \%)$ patients needed to visit their family doctor or local medical clinic for suture removal, whereas $7(9.8 \%)$ patients did so in the study group (see Table 2$)(p<0.001)$. The complication rate with respect to the sutured wounds was similar and not statistically significant in both the control and study groups (see Table 2).

Table 3 shows the comfort level of patients with future suture self-removal. There was no difference in comfort between the study group and the control group, and $96.3 \%$ of the patients would again remove their own sutures in the future. The process of suture self-removal was rated as "easy" or "moderately easy" by $93.8 \%$ of the study group.

\section{DISCUSSION}

Laceration repair and suture removal are common ED presentations. Although suture repair often needs a qualified ED provider, suture removals are discouraged in most EDs and are not complicated, and self-removal (often without proper equipment) is common. ${ }^{12}$ In fact, many health care providers feel that patients and/or family members are capable of safe suture self-removal.

A prospective study from Grand Rapids, Michigan, reported suture self-removal. ${ }^{12}$ The researchers found that $24 \%$ of patients removed their own nonabsorbable sutures and $85 \%$ of the patients would have preferred to remove their own sutures if they were given suitable instructions on how to do so. Doto and Killick performed a qualitative study using in-depth interviews 


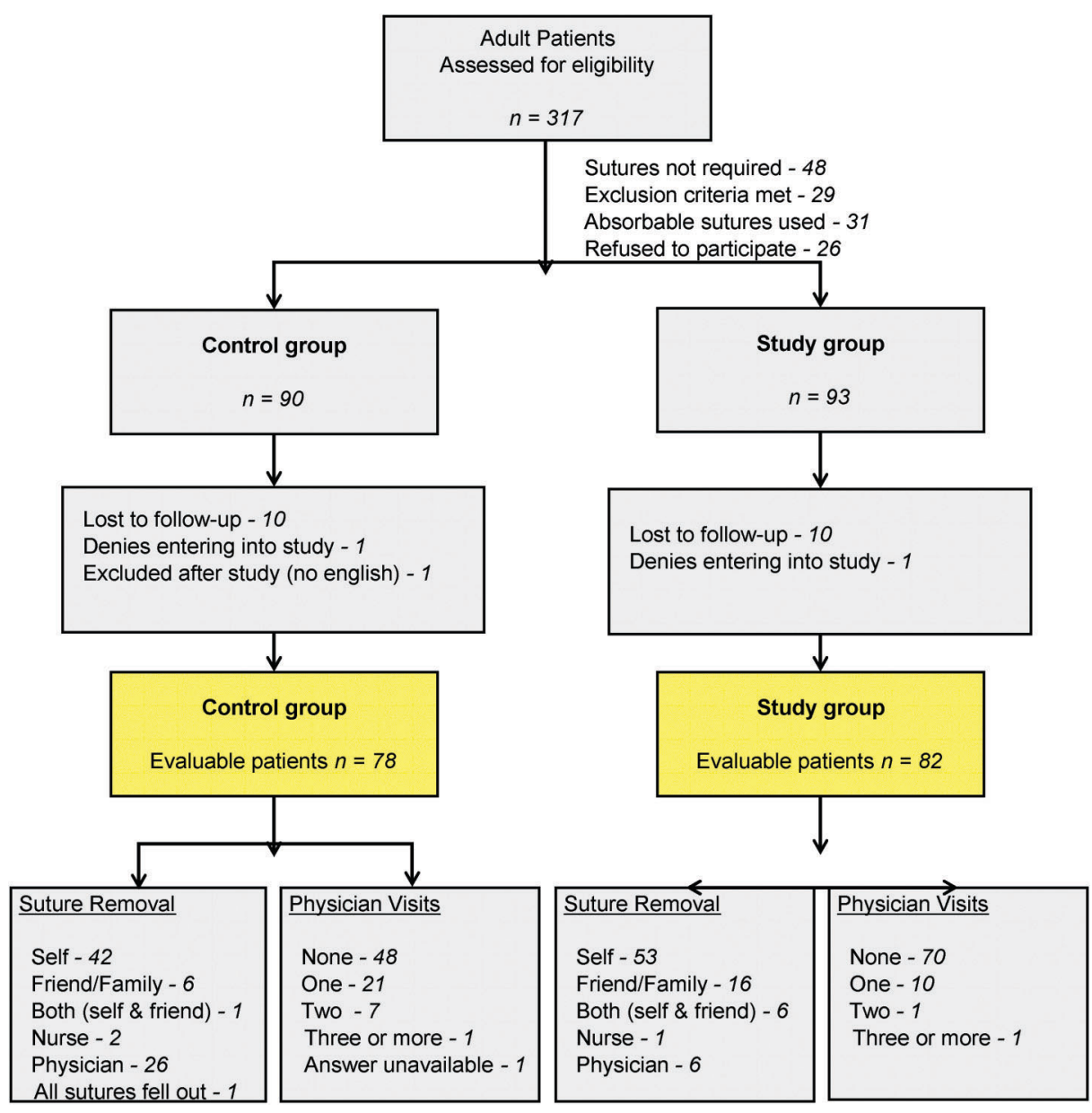

Figure 1. Selection of patients for the study. of women who removed their own sutures. ${ }^{13}$ Although their self-removal techniques differed, they found that their patients encountered few practical problems with suture self-removal, were open to self-removal in the future, and had a positive feeling about participating in their own care.

In this study, over $90 \%$ of patients in the intervention group successfully removed their own sutures. A higher than expected proportion of patients in the control group also elected to remove their own sutures, despite not receiving suture removal instructions or equipment. Control group patients may have been affected by the power of suggestion that suture self-removal was acceptable, simple, and not dangerous. Patients unwilling to remove their own sutures may have been more likely to decline participation in the study, which would

Table 1. Demographics of intervention and control patients in suture removal study

\begin{tabular}{|c|c|c|c|}
\hline \multicolumn{2}{|c|}{ Control group } & \multirow{2}{*}{$\begin{array}{c}\text { Intervention group } \\
42.5(14.6)\end{array}$} & \multirow{2}{*}{$\begin{array}{l}\text { p value } \\
0.99\end{array}$} \\
\hline Age, mean (SD) & 42.5 (14.9) & & \\
\hline Male, $n(\%)$ & 62 (81.6) & 65 (79.3) & 0.72 \\
\hline \multicolumn{4}{|l|}{ Location, $n(\%)$} \\
\hline Scalp & $6(7.7)$ & $3(3.7)$ & $0.32 *$ \\
\hline Face & $9(11.5)$ & 13 (15.9) & 0.43 \\
\hline Extremity & $59(75.6)$ & 66 (52.8) & 0.46 \\
\hline Trunk & $1(1.3)$ & $0(0.0)$ & $0.49^{*}$ \\
\hline
\end{tabular}




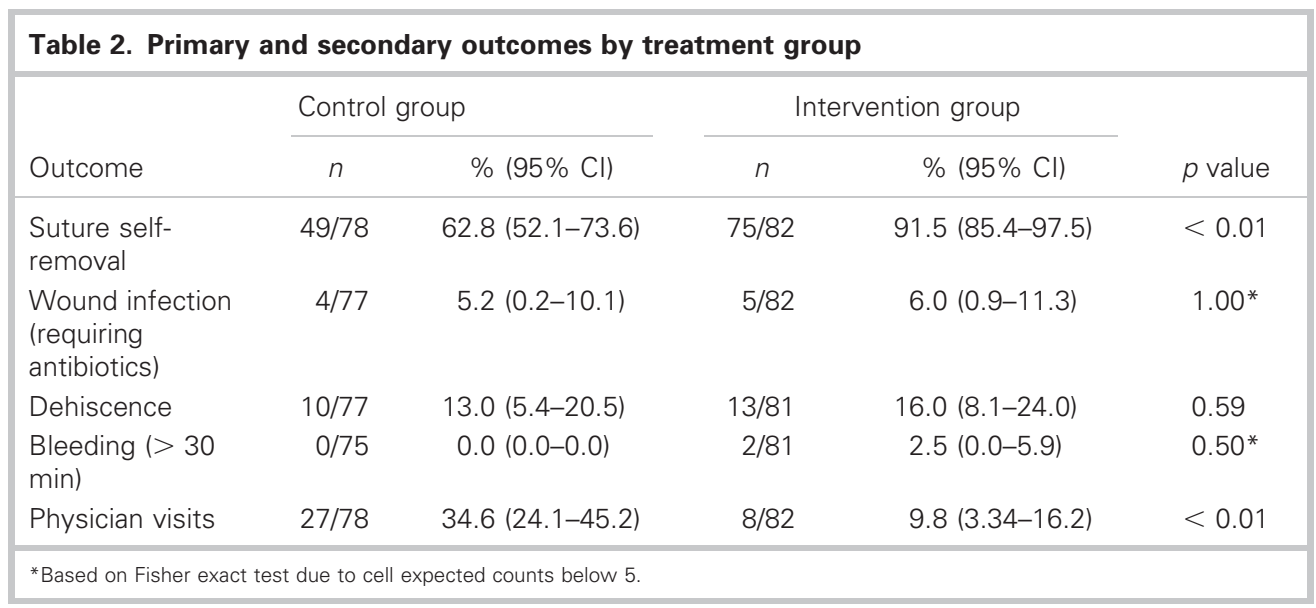

have resulted in a bias toward suture self-removal in both our control and intervention groups. Anecdotally, many patients randomized to the control group expressed disappointment that they would not receive suture removal instructions and equipment.

The literature is sparse and variable regarding wound infections. The reported proportion of wound infections in a sutured laceration varies depending on the site of the wound. ${ }^{5,7}$ For example, $1 \%$ of facial and scalp lacerations become infected, whereas infections in extremity lacerations have been reported to be as high as 7\%.7 Overall, wound infections range anywhere from 1.3 to $17.5 \% .^{7,14,15}$ The overall proportion of wound infections in this study was 9 of 160 patients $(5.6 \%)$, which is in keeping with the published literature. There was infrequent use of antibiotics in both intervention and control groups. One patient in the control group required intravenous antibiotics, and one patient in each group received oral antibiotics. All other patients with reported wound infections received local antibiotic ointment only. Complications were subjectively obtained from the patient during the telephone interview and were not verified by study investigators. It was not determined if the patients with "reported" wound infections who only used antibiotic ointment had "true" wound infections. Seaman and
Lammers found that patients were unable to recognize wound infections. ${ }^{16}$ In their study of 433 patients who had a sutured wound repair, 21 cases of infection were found. Only 11 cases were diagnosed by the patient ( $48 \%$ false-negative rate). The false-positive rate of detection of a wound infection by patients in their study was $8 \%$. The authors concluded that most traumatic wounds requiring suturing should have a follow-up examination by a physician before suture removal. The number of patients in our study requiring a systemic antibiotic for wound infections was very low (1.9\%). The reason for the low infection rates may have been that most complicated lacerations and patients with high-risk comorbidities were excluded from the study.

The recommendations for suture removal used in this study were based on good general principles of wound healing..$^{1,2,5-8}$ Wounds heal at varying rates depending on individual host factors. Premature suture removal may result in an increased risk of wound dehiscence and a poor cosmetic result. ${ }^{6}$ Sutures left in the wound too long may also result in poor cosmetic results, including permanent sinus tracts and suture imprints. ${ }^{6}$ Wound dehiscence was similar in both groups and in most cases was less than $5 \mathrm{~mm}$; however, it was difficult to determine the "true" proportion of

\begin{tabular}{|lcc|}
\hline \multicolumn{2}{|c|}{ Table 3. Opinions of patients regarding suture self-removal in the future } \\
\hline & Control group $(n=78) n(\%)$ & Intervention group $(n=82) n(\%)$ \\
\hline Very comfortable & $56(71.8)$ & $59(72)$ \\
Somewhat comfortable & $15(19.2)$ & $14(17.1)$ \\
Neutral & $2(2.6)$ & $5(6.1)$ \\
Somewhat uncomfortable & $2(2.6)$ & $3(3.7)$ \\
Very uncomfortable & $1(1.3)$ & 0 \\
\hline
\end{tabular}


wound dehiscence in this study. The amount of wound dehiscence was obtained subjectively from the patient during a telephone interview and was not actually measured by the patient or study investigators. Bleeding for more than 30 minutes occurred in two study group patients. This could have been avoided by providing the patient with information concerning the use of firm pressure on the wound in case of bleeding.

The sample size permitted adequate power to detect the study's primary outcome. Further studies involving larger cohorts of participants are needed to determine the advantages and safety concerns of suture selfremoval with respect to the secondary outcomes. Verification of wound infection and dehiscence by study investigators through scheduled follow-up patient visits or e-mailed digital photographs of the wound would be an improvement for a future study design. However, this would likely result in an inconvenience to the patient and a larger number of patients being lost to follow-up.

The literature suggests that all wounds considered to be high risk should have a mandatory 24 - to 48 -hour recheck by a physician. ${ }^{7}$ These include high-pressure injuries; animal or human bites; crush injuries with significant devitalized tissue; wounds involving exposed tendon, bone, or joints; and grossly contaminated wounds. ${ }^{7}$ In the event that these wounds are sutured, we would recommend that they not be considered for suture self-removal.

No formal cost-benefit evaluation was conducted in this study; however, cost savings were realized in physician visits. For example, the cost of visiting a physician or clinic for suture removal is not insignificant. Each physician visit in British Columbia incurs a bill to the Medical Services Plan of \$30.00. There are also patient-related "costs," including transportation, time, and the inconvenience of the patient having to book an appointment and take time away from work or family. The cost of the suture removal kit used in this study was $\$ 1.40$ per kit. Although the use of these kits could represent an overall saving in health care dollars, it would lead to a minor additional expense to individual hospital EDs.

\section{CONCLUSION}

Suture self-removal for simple lacerations is relatively safe and easy. In appropriately selected patients, complications such as wound infection, dehiscence, and bleeding are not significantly higher with suture self-removal than the current standard of care. For simple lacerations, if given proper instructions and equipment, many patients are willing and able to remove their own nonabsorbable sutures.

Acknowledgements: We would like to acknowledge Ms. Kerrie Lewis (research assistant), Mr. Michael Wasdell (statistician) from the Fraser Health Department of Evaluation and Research Services, and the Columbian Emergency Physicians Academic Working Group for their support.

Competing interests: None declared.

\section{REFERENCES}

1. Garcia-Gubern CF, Colon-Rolon L, Bond MC. Essential concepts of wound management. Emerg Med Clin North Am 2010;28:951-67, doi:10.1016/j.emc.2010.06.009.

2. Richardson M. Wound closure. Emerg Nurse 2003;11:25-32.

3. Karounis H, Gouin S, Eisman H, et al. A randomized, controlled trail comparing long-term cosmetic outcomes of traumatic pediatric lacerations repaired with absorbable plain gut versus nonabsorbable nylon sutures. Acad Emerg Med 2004;11:730-5.

4. Macdonald P. EP Current Practice Survey. RCH Online. Available at: http://www.rchemerg.com/Academics/AcademicProjects-at-ERH-and-RCH/Suture-Removal-By-Patients/EPCurrent-Practice-Survey (accessed June 4, 2011).

5. DeBoard RH, Rondeau DF, Kang CS, et al. Principles of basic wound evaluation and management in the emergency department. Emerg Med Clin North Am 2007;25:23-39, doi:10.1016/j.emc.2006.12.001.

6. Patel PR, Miller MA. Postcare recommendations for emergency department wounds. Emerg Med Clin North Am 2007;25:147-58, doi:10.1016/j.emc.2007.01.006.

7. Pfaff JA, Moore GP. Reducing risk in emergency department wound management. Emerg Med Clin North Am 2007; 25:189-201, doi:10.1016/j.emc.2007.01.009.

8. Capellan O, Holander JR. Management of lacerations in the emergency department. Emerg Med Clin North Am 2003;21: 205-31, doi:10.1016/S0733-8627(02)00087-1.

9. Wound care instructions adapted from the University of Virginia Department of Dermatology. Available at: http:// www.virginia.edu/uvaprint/HSC/pdf/051060.pdf (accessed March 15, 2010).

10. Image on suture removal instructions. Available at: http:// www.made-in-china.com/image/2f0j00gvQESBarOVqeM/ Suture-Removal-Kit.jpg (accessed March 15, 2010).

11. Bergman R. Stitching a cut. Image on suture removal instructions. Anatomy Atlases. Available at: http://www. anatomyatlases.org/firstaid/images/suturesD.jpg (accessed June 4, 2011).

12. Albert M, Daly A, Krueger J, et al. Self-removal of sutures by emergency department patients [abstract]. Ann Emerg Med 2009;54(3 Suppl):133, doi:10.1016/j.annemergmed.2009.06. $\underline{461}$. 
13. Doto TA, Killick SR. The use of a self-removal prolene suture after daycase laparoscopic surgery. Surg Laparosc Endosc Percutan Tech 2006;16:334-7, doi:10.1097/01.sle.0000 213743.08149.ce.

14. Alkan M, Gefen Z, Golcman L. Wound infection after simple suture at the emergency ward. Infect Control 1984;5:565.
15. Rutherford WH, Spence RAJ. Infection in wounds sutured in the accident and emergency department. Ann Emerg Med 1980;9:350-2, doi:10.1016/S0196-0644(80)80110-7.

16. Seaman $M$, Lammers R. Inability of patients to self diagnose wound infections. 7 Emerg Med 1991;9:215-9, doi:10.1016/ 0736-4679(91)90416-D. 